\title{
Influence of Peer Domain Factors on Substance Use among Female Students at the Nairobi and Thika Campuses of KMTC
}

\author{
Cerina Atieno Ouma
}

Africa Nazarene University

Kenya

\begin{abstract}
World drug report indicates growing accessibility to substances as a major world trend among ages 15 to 65 years. Globally, the use of substances by college students of all genders is a challenge and a public health concern. However, many studies on substance use focus on male students. This study had the purpose of assessing the influence of peer domain factors on substance use among female students at Thika and Nairobi campuses of Kenya Medical Training College (KMTC). The study adopted the ecological systems theory. Explanatory sequential mixed methods design (two-phase model) was used to collect quantitative data from participants on the subject; this was followed by the collection of qualitative data through an interview guide to get in-depth insight to help in explaining and elaborating the information gathered from the survey. The study population was 2474 female students. The study used stratified random sampling to select a sample of 344 respondents. Data from female students were gathered using semi-structured questionnaires and an interview guide. The data from the questionnaire were analyzed using descriptive statistics (frequency distributions, means, and percentages). Additionally, inferential statistics, correlation, and regression analysis were used to test the relationships between the study variables, while data from interviews were subjected to thematic analysis. The emergent findings were used to reinforce the findings from questionnaires. The study results show that that peer domain factors had a significant negative influence on substance use among the female students at KMTC $(\beta=0.787 ; p=0.000)$. In this regard, the similarity between peers is critical in influencing behavior. Therefore, having peers who do not use substances and having peers who disapprove of substance use is expected to lead to protecting female students from engaging in substance use. The study recommends that KMTC need to implement extensive substance prevention programs targeting female students to reduce risk factors associated with substance use. The preventive programs include guidance and counseling, peer counseling and mentorship programs and, advocacy campaigns. The interviews added that there was a need to establish and finance advocacy programs backed by social media to enhance the dissemination of information on the negative influence of substance use.
\end{abstract}

Keywords: Peer Domain Factors, Substance Use, Female Students, KMTC, Nairobi, Thika Campuses

\section{INTRODUCTION}

This study focused on peer and substance use among female Kenya Medical Training College students. Peer factors were the independent variables in the study while substance use (frequency of use, levels of risk, and commonly used substances) was the dependent variable. World Health Organization (WHO) indicates that more than 15.3 million people globally have disorders that emanate from substance use [1]. DSM-5 states that substance use is the recurring use of substances that lead to health problems, failure to meet major responsibilities, or functional impairment [2]. Notwithstanding the extensive prevention efforts, there has been an increase in unwarranted substance use currently among young female students which is an indication of risk [3].

Further, the World Drug Report of 2017 indicates that an estimated 250 million people aged between 15 to 64 years accessed and consumed at least one substance in 2014. Moreover, the report indicates that over 29 million people globally suffer from disorders that emerge from substance use [4]. There has been an upward surge in substance use amongst women in general and young girls in particular. Experts observe that up to 3 million young female students indulge in substance use, and 25 percent of the users engage in the use of more than one substance [5].

In addition, the evidence-based ecological structure shows that no single factor can explain ones' vulnerability to substance use. This study envisages that a student's vulnerability is the result of the influence of peer domain factors. These factors play an important part in modelling behaviour and highly influences female substance use, acting as a major influence in the process of decision making and the formation of social relationships. Hodder, Freund, Bowman, Wolfenden, Gillham, Dray, and Wiggers in an Australian study showed an association of peer influence on smoking and alcohol use behaviour amongst young adults [6]. Furthermore, peer similarity, friends' attitudes in smoking, and alcohol use were among the strongest smoking and alcohol use 
among female students.

Besides, the World Drug Report of 2017 reported that females aged between 18 to 24 years in Africa are increasingly using locally available substances. However, among the overall population, alcohol and pain medications are the most commonly used substances among females [4]. Those aged between 25 to 35 years have the highest past-year use and lifetime use of alcohol and pain medications. Equally, among females' lifetime use of prescription medication, heroin and cocaine are almost three times lower among people aged 36 years old as compared to ages 18 and 24 years.

In addition, the National Campaign against Drug Abuse Authority (NACADA) revealed the use of substances of choice as a public health problem in Kenya [7]. The study showed that for those aged between 15 and 24 years, 1.5 percent used bhang, 4.7 percent khat, 6.2 percent tobacco products while a high of 11.7 percent was using alcohol. The use of alcohol among the youth was higher in males compared to females (18.1 percent and 5.6 percent respectively).

In another study focused on KMTC, most study subjects reported low risk for alcohol use (98.1 percent), 1.7 percent reported moderate risk, while 0.25 percent reported a high risk of alcohol use. The study also found out that females were at a lower risk of alcohol use (99.15 percent) compared to males (97 percent) [8]. However, the study concluded the existence of a risk to substance use in KMTC. The use of substances among female students remains a critical scope of the study as a result of the consequences of the use of substances of choice to user's health and future. A study on tolerance to substance use in urban slums in Kenya showed that females had higher scores on the resilience index compared to males [9]. The resilience factors in the study included parental involvement as agents of social control, empowerment programs, and policies to enhance access to education and recreation and opportunities for civic involvement.

Moreover, studies on the influence of peer domain factors and substance use were carried out in developed countries like Europe and America. The risks faced by youth and the environmental conditions present in these developed nations may not be similar to our local Kenyan context and hence these findings may not be generalized to the Kenyan context. Generally, studies on peer factors influencing female substance use in medical schools are minimal. Female students' substance use problems remain issues whose impact has been underestimated. Therefore, there was the need to carry out this study in KMTC to establish the influence of peer domain factors on substance use among female students.

\subsection{Statement of the Problem}

Despite the vast knowledge and practical training on health and being agents of change in matters of individual and community health, female medical students still engage in substance use. A study focused on KMTC revealed that students face the risk of substance use. Though most students had a lower risk to the use of alcohol ( 98.1 percent), there is a considerable population (1.7 percent) who had moderate risk and another 0.2 percent that had a higher risk to the use of alcohol [8]. The risk of alcohol use was lower among females (99.15 percent) compared to males (97 percent). However, the study does not attempt to examine these differences between substance use among males and females in the context of peer domain factors.

Moreover, the study by Muriungi et al. indicated that there were a considerable number of female students at risk of substance use [8], Gathumbi posits that substance use among male students is usually higher than in female students, and hence the various studies on male students [10]. This creates an information gap in Kenya regarding the prevalence of substance use among female medical students. This informed the study which focused on the influence of peer domain factors on substance use among female students at KMTC.

Even though there are several studies undertaken on the influence of the three variables on substance use [11], [12], [5], important literature gaps remain. Most existing studies were conducted in developed nations. However, the context in these countries may not be similar to that of Kenya. This means that the study findings may not expressly cast light on the state of affairs among female students in Kenya. In addition, most reviewed studies were conducted amongst secondary school students [10], [5], [11]. These findings may thus not expressly relate to this current study since the secondary school environment and population are distinct from those of tertiary colleges such as KMTC. In this context, the motivation of this current study was to establish the influence of peer domain factors on substance use among female students at KMTC.

\subsection{Objective of the Study}

The objective of the study was to establish the influence of peer domain factors on substance use among KMTC female students. 


\section{LITERATURE REVIEW}

\subsection{Theoretical Framework}

The study was guided by Bronfenbrenner's ecological systems theory [13]. Ecological Systems Theory (EST) provided a theoretical framework to study individuals in ecological contexts: studying individuals, their environment, and how the individual interacts with each other and their environment. Abstractly, EST is being used to prompt focus on influence at different levels, informing the advancement of models in different contexts to describe events including protective factors and risk of substance use. EST focuses on identifying factors influencing substance use as per individuals' context and guides strategies within and beyond an individual's control to include the environment and its interaction with the individual. This makes this theory better placed to the study in explaining peer domain factors influencing female students' substance use in a medical training college context.

Originally, Bronfenbrenner illustrates ecological systems at various levels as intertwined, thus informing EST's graphical depiction as a set of circles [14]. Bronfenbrenner states that discovering persons is a composite process. Later, in 1986, he posits that understanding an individual and their environment needs to be fully examined including the school set up, ones' way of life/ culture, community, home among other contexts, stressing that the person and their context are interrelated [15]. The complementary relations between a person and various extrinsic systems are regarded as central procedures that determine individuals' resilience or risk to substance use.

Additionally, the ecological systems theory depicts the environment of an individual to consist of four levels: the macro system, microsystem, exosystem, and mesosystem [16]. The immediate environment is the microsystem that the individual lives in, which comprises the immediate family, school, and home environment. This informed the study in that the family and college environment of the targeted KMTC female students could have influenced their substance use behaviour. The mesosystem entails how the different aspects of the microsystem interact with each other to affect the individual. The exosystem comprises places and other people that individuals' may not regularly relate with but has an influence on them such as the neighbourhood, community members, and parents' workplaces among others.

Lastly, the macrosystem comprises aspects such as laws, economic factors, religion, cultural values, and other such aspects in the external environment which may have a negative or positive influence on the individual. This explains that individual factors such as religious beliefs and institutional factors such as policies by KMTC regarding substance use may influence substance use among female students. The EST has been applied in many studies across various disciplines including studies on vulnerability to substance use [6], [17] and in assessing resilience to substance use [18].

This theory relates to this current study in various ways. It identifies the factors that influence substance use among individuals (female students in the case of this study). In this regard, the theory makes it clear that the environment of female students directly or indirectly influence their propensity to use various substances. The environment of the female students such as the peer domain factors could influence their propensity to use the substance of choice.

\subsection{Empirical Review}

\subsubsection{Peer Domain Factors and Substance Use}

A study focused on Iceland showed an association of peer influence on smoking and alcohol use behaviours amongst teenagers. The study also noted that peer similarity in smoking and alcohol use was among the strongest smoking and alcohol use behaviour predictor [5]. The study established that friends' or peers' attitudes towards smoking were vital in influencing individual's substance use behaviour. Peer disapproval of smoking or use of the substance of choice was a protective factor to adolescent peers. Results indicated that peer influence and similarity on substance use and perceived peer reactions are vital variables. Friends are crucial to teenagers in their developmental stage and having friends who engage in substance use highly influences substance use behaviour amongst female students. These findings are in line with this current study that envisages that peers could influence substance use among female students.

For instance, a study focused on Australia assessed the relationship between teen's unwarranted use of the substance of choice and protection from one's environment. The study established an inverse relationship between 'pro-social peers' and substance use [6]. However, the study established that 'peer caring relationships' were related to individuals' use of the substance of choice. Furthermore, a South African study posits that young people whose associates engage in the use of substances are at higher risk to use readily available substances of choice [19] while getting involved in various forms of violence or victimization and are likely to perpetrate violent acts [20].

In addition, other studies have established that the youth who experience frequent reports to authorities are potentially likely to be exposed to public drunkenness [19]. This current study sets out to establish how these findings may apply to female 
students in Kenya. In a longitudinal study among young people in Uganda, it was established that the use of various substances of choice by peers significantly predict violence amongst youth [21]. However, unplanned communities were also found to be higher predictors of high incidence of the use of locally available substances among adolescents. In addition, the youth who report greater disorganization in their communities are more at risk of the use of substances as opposed to those who report less disorganization within their communities. This shows that a disorganised society made substance use among the youth rampant and this encouraged those who engage in various substances to recruit peers into the vice.

Similarly, conformity of behaviour, interest, values, and attitudes among the youth have been established as major influencing factors in the development of adolescents, this, therefore, leaves them with minimal resistance against substance use. The more parents are not able to act with authority consistently, the more the adolescents are likely to conform to their peers [22]. In Uganda, adolescents have an overwhelming experience of stress from deaths, wars, and also substance use, but regardless of the adversities, several of them present resilience to substance use [23]. Peer pressure is regarded as key in adolescents' decision to engage in substance use. Since the study was not focused on Kenya, it is important to test the credibility of these findings among female students in Kenya.

Bernard underlines that significant achievements of resilience have resulted from various studies as; positive psychology which focuses on strengths that enable people or communities to flourish, the overall health of an individual throughout one's lifespan, and the investment in the welfare of the youth [24]. Search Institute asserts that young persons with fewer assets are highly likely to perpetuate risky behaviours like substance use and deviant behaviour [25]. Likewise, scholars hypothesize that to strengthen the underlying protective factors linked with resilience to substance use, some caring and personal relationships have to be formed, to increase the chances of young people making conscious realistic healthy choices that can lead to the success of students [26]. Having supportive friends is one key protective factor that was mentioned in the study.

\subsection{Summary of Review of Literature and Research Gap}

The reviewed literature leaves a few gaps that the current study sought to address. First, most reviewed studies were conducted in developed nations [11], [12], [5]. The context in these countries may not be similar to the local Kenyan context and hence these studies cannot be generalized to the Kenyan context. Additionally, most of the reviewed studies were conducted amongst secondary school students [10], [5], [11]. The secondary school environment and the population is distinct from the population and environment in a tertiary college such as KMTC.

In addition, positive adaptation despite adverse circumstances is a multi-dimensional and dynamic process that evolves and entails the reciprocal exchanges between individuals and their environment. Young female students are increasingly engaging in substance use. However, there is a deficiency of studies that has female medical students as the target population with regards to peer domain factors and substance use at KMTC. Those that focused on females such as Good and McKay, did not focus on substance use [27] while the study by Bot had adolescents as the target population [28]. This study bridged the empirical gap by assessing peer domain factors and substance use among female students in a tertiary college, KMTC.

Further, studies on peer factors among college students are few, the capacity and competence of KMTC staff on mental health may not enable them to adequately identify these factors among female students. Further, studies analysed show that substance use is a public health problem that exists all over the globe. Effects of trying out on historic and newer substances lead to higher substance use and dependence on the substance of choice. Experimentation affects young female students to newer complex emerging substances. None of these studies was conducted on peer domain factors and substance use among female students at KMTC, a meeting point of diverse cultures. This study, therefore, sought to fill these gaps and establish the factors influencing substance use to inform practical interventions.

\section{METHODOLOGY}

\subsection{Research Design}

The researcher adopted an explanatory sequential mixed methods design that involved the collection of quantitative data and analysis followed by collection and analysis of qualitative data from respondents regarding peer domain factors and substance use among female KMTC students to gain more insight and to expound quantitative results. Consequently, explanatory sequential mixed methods design was used to gather quantitative data collection on peer domain factors and relate them to substance use by the female students at KMTC by using both questionnaire and interview guide.

\subsection{Research Site}

The study was conducted at KMTC Thika and Nairobi campuses located in Kiambu and Nairobi counties. The researcher 
had ease of access and developed an immediate rapport with participants. KMTC has been selected as the study site that was informed by the findings of the study by Muriungi et al. stating that female students at KMTC, face the risk of substance use and hence the need to build students' resilience backed by empirical evidence to mitigate the challenge [8].

Additionally, KMTC, Nairobi has the largest capacity of students, with a total of 2174 female students. The situation and locality is Ngong road, 3 kilometres off Nairobi central business district within Nairobi city, adjacent to Kenyatta National Hospital. KMTC Thika has a relatively smaller population of female students, having a total of 300 female students. The situation and locality are 50 kilometres off Nairobi in Thika town. The study focused on KMTC due to the high risk of substance use among female students [8]. Thika and Nairobi campuses were selected due to the high levels of unwarranted substance use in urban areas in Kenya where these campuses are located [9].

\subsection{Target Population}

The population is the cluster of components used to arrive at deductions and is of interest in any study [29]. This study targeted all KMTC female students at all levels at Nairobi and Thika campuses. The population of female students from KMTC Nairobi and Thika campuses that were targeted was 2474 at the time of the study, March 2018, as per the records from principal Nairobi and Thika campuses. They were recruited using the class placement lists provided by the principals.

\subsection{Study Sample and Sampling Procedure}

This section presents the sample size and sampling procedure that was employed in the study. A sampling frame is a list that comprises the member of the population [29]. The study population was 2474 female students. Sampling was aided by the sample size calculation formula by Yamane [30] as indicated by Cooper and Schindler [31]. A level of statistical significance of 5 percent was used to minimize sampling error.

$$
n=\frac{N}{1+N(e)^{2}}
$$

In the formula;

$$
\begin{aligned}
& \mathrm{n}=\text { sample size } \\
& \mathrm{N}=\text { population size } \\
& \mathrm{e}=\text { margin of error }(0.05) . \\
& \qquad \mathrm{n}=344
\end{aligned}
$$

The 344 sampled respondents were selected randomly and proportionately from all the female students from the two campuses.

The Researcher adopted proportionate stratified sampling to select the study sample. The strata included the Nairobi and Thika KMTC Campuses. From each campus (stratum), a sample of 86 was selected from Thika and 258 from Nairobi making the sample of 344 female students for the study. The Researcher adopted simple random sampling to pick out the sample for the study by allowing willing participants to pick papers indicating Yes or No.

\subsection{Data Collection}

\subsubsection{Data Collection Instruments}

The study used questionnaires and interviews for the collection of data. Cooper and Schindler suggest that the use of questionnaires is cost-effective in collecting data and reaching the study sample is easier while interviews accord the participants time to freely provide information without the limitation of a predetermined set of questions [31]. Paper-and-pen self-administered questionnaires containing structured items were developed as per the study's objectives.

The paper-and-pen questionnaire had various sections: section A; social and demographic characteristics of the respondents, section B; Substance use as guided by the Alcohol, Smoking, and Substance Involvement Screening Test (ASSIST v3.0) a modified standardized test adapted from World Health Organization [32], section C; had closed questions rated on a five-point scale seeking information for peer domain factors. A questionnaire was given to all female students selected in the sample to collect data relating to female student's substance use in Nairobi and Thika campuses. On their part, interviews were conducted among 10 female student leaders drawn from the sampled students. The interview guides contained questions linked to the study questions. 


\subsubsection{Pilot Testing of Research Instruments}

Pilot testing was carried out to determine the accuracy, clarity, and suitability of the paper-and-pen questionnaire. Mugenda and Mugenda observe that a pilot test is a try-out of the main study on a small scale to test unexpected problems and to minimize such errors and increase success rate [33]. Piloting aided to administer the paper-and-pen questionnaire, and gauging the time limit for the completion of the questionnaire.

Thirty-four female students from KMTC, Karen campus were used in the pilot test. This was 10 percent of the targeted study sample [33]. The pilot test checked participants' responses and pointed out necessary amendments that were required to make the questionnaire easy to understand. Female students from the KMTC Karen campus were used for pilot testing of the questionnaire since the researcher held an assumption that behavioural patterns on substance use were corresponding, and that the college faced similar challenges as Nairobi and Thika.

\subsubsection{Instrument Reliability}

Cronbach's alpha assesses internal consistency through which a research participant responds to the different items and hence applicable as a measure of scale reliability. Cooper and Schindler indicates that a high value of the Cronbach alpha denotes high reliability whereas a low value denotes low reliability [31]. An alpha value of 0.7 and above is permissible while a value of less than 0.7 will require amendment or removal of some items. Thirty-four female students from KMTC, Karen campus were used in the pilot test which was used to test the reliability and appropriateness of the questionnaire that was used in data collection. However, responses from pilot testing were entered into SPSS and Cronbach alpha reliability statistics computed. Adjustments were made to some parts of the questionnaire until the researcher established that all the questionnaire items were relevant and appropriate with Cronbach alpha of 0.7 and above as shown in Table 1.

Table 1 Reliability Statistics

\begin{tabular}{|l|c|c|}
\hline Items & Number of Items & Cronbach's Alpha \\
\hline Peer domain factors & 3 & 0.739 \\
\hline Substance use & 4 & 0.725 \\
\hline
\end{tabular}

\subsubsection{Instrument Validity}

The validity of the study instruments was measured in different ways. To begin with, face validity, which is a "subjective assessment of whether the test measures what it was supposed to or not". Face validity was measured by assessing the ease with which the study participants respond to the questions contained in the questionnaires. Any ambiguous questions were identified and adjusted appropriately.

Additionally, content validity, ensured that the research tools "offered an adequate investigation of the study. Content validity questions were ensured through expert's opinion by university supervisors. Their input was used to ensure that the research instruments were suitable for use and that the data collected could answer the research questions. Adjustments, corrections, and additions were made to the research instrument.

Consequently, construct validity, "the extent to which a set of measured items reflect the theoretical latent construct that the items were designed to measure" [31]. The researcher ensured construct validity by formulating the study questions in line with research objectives. In this regard, the questions in the research instruments were formulated based on the literature reviewed.

\subsubsection{Data Collection Procedure}

A letter of introduction and clearance from Africa Nazarene University, Board of Post Graduate Studies was obtained. The permit was granted by the National Commission for Science, Technology, and Innovation (NACOSTI), and permission was obtained from County administration offices, in Nairobi and Kiambu counties respectively. The permit from NACOSTI was presented to the Director/Assistant Director in charge of research whereby authority was granted to carry out the study, and the Principal Nairobi campus issued a memo to all departments introducing the Researcher.

Consequently, the head of each department introduced the Researcher/ Assistant to the lecturers or class/participants. After the introduction, the study's participants were informed of the research purpose and were assured of their anonymity, confidentiality, and informed consent in participation in the study. Paper-pencil questionnaires were distributed by the Researcher and/or Assistants to the participants via yes/ no criteria. The Researcher allowed the participants twenty minutes to answer the questionnaires. After the lapse of the time, the Researcher collected the questionnaires followed by a short speech thanking the 
participants for their participation in the study. Appointments were made with the student leaders at a later time. Thereafter, the Researcher visited the campuses and conducted the interviews. This took four non-consecutive days.

\subsection{Data Processing and Analysis}

Data collected from female students were analysed quantitatively and qualitatively. Quantitative data collected was analysed using Statistical Package for Social Sciences (SPSS version 23). Descriptive statistics, frequencies, percentages, and means were used to analyse the quantitative data. Inferential statistics, Pearson correlation, and multiple regression analysis were used to test the relationships between the study variables. Conversely, data from interviews were subjected to thematic analysis. The emergent findings were used to reinforce the findings from the questionnaires. The conclusions were derived from the analysed data, translating to the recommendations and suggestions for further studies.

\section{DATA ANALYSIS AND INTERPRETATIONS}

\subsection{Response Rate}

The study targeted 344 female students of Thika and Nairobi KMTC. Out of 344 questionnaires, 315 were filled and collected from the participating female students. This was a return rate of 92 percent. The findings presented in this section relate to the responses provided by the 315 female students from the two campuses of KMTC. A 60 percent and above response rate is adequate for a paper-based questionnaire survey [31]. The findings are derived after analysis through SPSS which provided both descriptive and regression statistics.

\subsection{Social Demographic Characteristics of the Respondents}

General information about the participants that were observed in the study included the religious affiliation of the respondents, age, type of secondary school they attended, and the type of family that the respondents were brought up in. Additionally, information regarding substance use in the past, and whether the respondents had never used, was still using, recovering, or fully recovered was collected. Information on the social demographic characteristics of the participants is presented in Table 2.

Table 2 Social Demographic Characteristics of Respondents

\begin{tabular}{|c|c|c|}
\hline Religion & Frequency & Percent \\
\hline Christian & 278 & 89 \\
\hline Muslims & 33 & 11 \\
\hline Hindu & 2 & 1 \\
\hline Total & 313 & 100 \\
\hline \multicolumn{3}{|l|}{ Age Group } \\
\hline 18 - 20 years & 123 & 39.1 \\
\hline $21-23$ years & 157 & 49.8 \\
\hline 24 years and above & 29 & 9.2 \\
\hline Non-response & 6 & 1.9 \\
\hline Total & 315 & 100.0 \\
\hline \multicolumn{3}{|l|}{ Type of School } \\
\hline Boarding & 177 & 56.2 \\
\hline Day & 30 & 9.5 \\
\hline Mixed & 61 & 19.4 \\
\hline Girls only & 47 & 14.9 \\
\hline Total & 315 & 100.0 \\
\hline Family Backgrou & & \\
\hline
\end{tabular}


International Journal of Advances in Scientific Research and Engineering (ijasre), Vol 7 (9), September -2021

\begin{tabular}{|l|c|c|}
\hline Type of family & & 66.8 \\
\hline Nuclear family & 207 & 18.1 \\
\hline Extended family & 56 & 11.3 \\
\hline Single parent family & 35 & 3.9 \\
\hline Step/ blended family & 12 & $\mathbf{1 0 0 . 0}$ \\
\hline Total & $\mathbf{3 1 0}$ & \\
\hline
\end{tabular}

Regarding the religion of respondents, study results are presented in Table 2. A total of 313 respondents indicated their religion, 89 percent of the respondents were Christians, 11 percent Muslims, and one percent Hindu. The ages of the respondents were also determined in the study and a total of 309 respondents indicated their age. Those aged between 21 and 23 years were 49.8 percent while those aged 24 years and above were 9.2 percent. The mean age was 20.98 years. The study also found out the type of secondary school that the respondents had attended. Study results demonstrate that most of the participants (56.2 percent) attended boarding secondary schools while only 9.5 percent had attended day schools. Lastly, the study also established the type of family that the respondents were brought up in. The study findings indicate that 67 percent of the respondents were brought up in nuclear families, 18 percent in extended families, 11 percent in single-parent families while 4 percent were brought up in step (blended) families.

\subsection{Substance Use at KMTC}

There were five measures for the extent of substance use that included: - status of substance use, non-problematic use, harmful use, non-medical use, and polydrug use. Status of substance was measured by a rating scale that classified the participants as follows: - recovering, still using, and never used. Non-problematic use was measured by ever used and past three months' use.

As a result, harmful use of substances was measured by the following indicators:- female students who had a stronger urge to use the substance of choice within three months preceding the study; whether female students use of the substances resulted in legal, financial, social issues and health-related challenges three months preceding the study; participants failure to do their obligations as expected of them due to substance use in the past three months preceding the study, and participants' attempted and was unsuccessful in controlling, cutting down or stopping the use of the substance of choice in the last three months before the study. Non-medical use was measured by whether participants had ever used substances by injection for non-medical use within and without three months preceding the survey. The study also analysed poly-drug use (Those who were using more than one substance) among female students. Poly-drug use was measured by ten measures. The substances included tobacco products, alcohol, cannabis, pain medications, and sleeping pills. The findings and their implications are shown in the following section.

Similarly, the status of substance use was measured by a rating scale that classified the participants as follows: recovering, still using, and never used. Female students who participated in the study were requested to indicate their status of substance use. The results are presented in Table 3 .

Table 3 Status of Substance Use

\begin{tabular}{|l|c|c|}
\hline Status & Frequency & Percent \\
\hline Recovering & 29 & 9.2 \\
\hline Still using & 30 & 9.5 \\
\hline Never used & 183 & 58.1 \\
\hline Non-response & 73 & 23.2 \\
\hline Total & $\mathbf{3 1 5}$ & $\mathbf{1 0 0 . 0}$ \\
\hline
\end{tabular}

The respondents were to indicate whether they were recovering, still using, or had never engaged in substance use. Results presented in Table 3 indicate that 58.1 percent indicated that they have never engaged in substance use while 23.2 percent did not respond to the question. The female students who indicated that they were recovering were 9.2 percent while 9.5 percent were still engaging in substance use. This indicated a high prevalence rate of substance use since 9.5 percent were still using various substances of choice. Furthermore, problematic use of the substance of choice was measured by ever used (lifetime use) and past-month use (used within three months preceding the survey). The findings are presented in Table 4. 
International Journal of Advances in Scientific Research and Engineering (ijasre), Vol 7 (9), September -2021

Table 4 Female Students who had Ever used Substances

\begin{tabular}{|c|c|c|c|c|}
\hline \multirow[t]{2}{*}{ Substances } & \multicolumn{2}{|c|}{ NO } & \multicolumn{2}{|c|}{ YES } \\
\hline & $\mathbf{F}$ & $\%$ & $\mathbf{F}$ & $\%$ \\
\hline Tobacco products (cigarettes, chewing tobacco) & 262 & 94 & 16 & 6 \\
\hline Alcohol (wine, spirits, beer) & 191 & 64 & 105 & 35 \\
\hline Cannabis (weed, pot, grass) & 249 & 87 & 36 & 13 \\
\hline Sleeping pills & 228 & 83 & 48 & 17 \\
\hline Pain medications & 103 & 36 & 183 & 64 \\
\hline
\end{tabular}

Regarding 'ever use' of substances, results shown in Table 4 illustrate that 64 percent of the participating female students had at one time engaged in illicit use of pain medications, 35 percent had used alcohol, 17 percent used sleeping pills, 13 percent engaged in cannabis use while only 6 percent had engaged in the use of tobacco products. Results regarding those who had engaged in substance use in the three months before the study were sought. Table 5 presents these findings.

Table 5 Female Students Engaged in Substance Use in the Preceding Three Months

\begin{tabular}{|l|c|c|c|c|c|c|}
\hline Substances & Never $(\boldsymbol{\%})$ & $\begin{array}{c}\text { Once or twice } \\
(\boldsymbol{\%})\end{array}$ & $\begin{array}{c}\text { Monthly } \\
(\boldsymbol{\%})\end{array}$ & $\begin{array}{c}\text { Weekly } \\
(\boldsymbol{\%})\end{array}$ & $\begin{array}{c}\text { Daily or almost } \\
\text { daily }(\boldsymbol{\%})\end{array}$ & Total \\
\hline Tobacco products & 89 & 8 & 0 & 3 & 0 & 100 \\
\hline Alcohol & 71 & 20 & 4 & 4 & 1 & 100 \\
\hline Cannabis & 88 & 6 & 2 & 4 & 0 & 100 \\
\hline Sleeping pills & 81 & 12 & 6 & 0 & 4 & 100 \\
\hline Pain medication & 39 & 43 & 12 & 2 & 1 & 100 \\
\hline Average (\%) & 74 & 18 & 5 & 2 & 4 & 315 \\
\hline Average (F) & 232 & 56 & 15 & 8 & & 4 \\
\hline
\end{tabular}

The findings as shown in table 5 demonstrate that female students who had engaged in the use of pain medications once or twice in the three months before the study were 43 percent (Table 5). Moreover, results show that 20 percent had engaged in alcohol use, 12 percent had used sleeping pills, 8 percent had used tobacco products while 6 percent had used cannabis during three months before the study. With 18 percent indicating that they used substances once or twice a day, it is evident that there was moderate use of substances. This emanates from the fact that 18 percent were close to half of those who were engaging in substance use. These findings indicate that the most used substance in the preceding three months before the study was pain medications, overall various kinds of substances were being used by female students at KMTC.

In addition, harmful use of various substances was measured by the following indicators: female students had a strong urge to indulge in substance use in three months preceding the study; and whether the participant's use of the substances led to legal, financial, social, or health problems three months preceding the study; whether participants had failed in their normal duties as expected of them as a result of the use of the substances in the past three months, the study established whether substance use affected the performance and that the female students had attempted to control and failed, or to reduce or abstain from using any of the substances in the last three months. Moreover, the level of harmful use was calculated by summing up 20 items that were measuring the harmful use of the substances. Three levels were established thus; low risk of harmful use (20-46), moderate risk of harmful use (47-73), and high risk of harmful use (74-100). These findings are presented in the following sections.

Moreover, the study assessed how often the respondents had a robust urge to use the listed substances three months before the study as shown in Table 6 . 
International Journal of Advances in Scientific Research and Engineering (ijasre), Vol 7 (9), September -2021

Table 6 Female Students with Strong Desire for Substance Use in the Preceding Three Months

\begin{tabular}{|c|c|c|c|c|c|c|}
\hline Substances & Never $(\%)$ & $\begin{array}{c}\text { Once or twice } \\
(\%)\end{array}$ & $\begin{array}{c}\text { Monthly } \\
(\%)\end{array}$ & $\begin{array}{c}\text { Weekly } \\
(\%)\end{array}$ & $\begin{array}{l}\text { Daily or almost } \\
\text { daily }(\%)\end{array}$ & Total \\
\hline Tobacco products & 93 & 4 & 2 & 0 & 1 & 100 \\
\hline Alcohol & 76 & 16 & 5 & 2 & 2 & 100 \\
\hline Cannabis & 87 & 5 & 1 & 4 & 3 & 100 \\
\hline Sleeping pills & 91 & 5 & 1 & 2 & 1 & 100 \\
\hline Pain medications & 61 & 24 & 7 & 1 & 7 & 100 \\
\hline Average (\%) & 81 & 11 & 3 & 2 & 3 & 100 \\
\hline Average (F) & 256 & 34 & 10 & 6 & 9 & 315 \\
\hline
\end{tabular}

Study findings (Table 6) revealed that 24 percent had experienced a robust urge or desire to use pain medications, 16 percent had a desire for alcohol, 5 percent had a strong urge for cannabis, and sleeping pills, while 4 percent had a strong urge for tobacco products. The study also enquired from the respondents whether they had in the three months before the study engaged in substance use that led to legal, financial, health, or social problems.

Table 7 Female Students whose Substance Use Led to legal, financial, health, or social problems

\begin{tabular}{|c|c|c|c|c|c|c|}
\hline Substances & Never (\%) & $\begin{array}{c}\text { Once or twice } \\
(\%)\end{array}$ & $\begin{array}{c}\text { Monthly } \\
(\%)\end{array}$ & $\begin{array}{c}\text { Weekly } \\
(\%)\end{array}$ & $\begin{array}{c}\text { Daily or } \\
\text { almost daily } \\
(\%)\end{array}$ & Total \\
\hline Tobacco products & 97 & 1 & 1 & 1 & 0 & 100 \\
\hline Alcohol & 78 & 18 & 2 & 1 & 1 & 100 \\
\hline Cannabis & 88 & 8 & 1 & 3 & 0 & 100 \\
\hline Sleeping pills & 84 & 12 & 1 & 2 & 1 & 100 \\
\hline Pain medication & 71 & 21 & 6 & 2 & 0 & 100 \\
\hline Average (\%) & 84 & 12 & 2 & 2 & $\mathbf{0}$ & 100 \\
\hline Average (F) & 263 & 38 & 7 & 6 & 1 & 315 \\
\hline
\end{tabular}

Findings from the study presented in Table 7 established that 12 percent had once or twice engaged in illicit use of sleeping pills which led to legal, social, physical health, or financial challenges once or twice. Further, results indicated that 18 percent had once or twice engaged in alcohol, 21 percent engaged in pain medications, 8 percent in cannabis, and 1 percent in tobacco products which led to legal, financial, health, or social problems.

The study also assessed how substance use affected the everyday roles and responsibilities of female students. Respondents were required to indicate how often substance use in the three months preceding the study had made them fail to do their duties. 
International Journal of Advances in Scientific Research and Engineering (ijasre), Vol 7 (9), September -2021

Table 8 How Often Substance Use Affected Performance

\begin{tabular}{|c|c|c|c|c|c|c|}
\hline \multirow[t]{2}{*}{ Substances } & \multirow[t]{2}{*}{ Never $(\%)$} & \multirow[t]{2}{*}{$\begin{array}{c}\text { Once or twice } \\
(\%)\end{array}$} & Monthly & Weekly & \multirow[t]{2}{*}{$\begin{array}{c}\text { Daily or almost } \\
\text { daily }(\%)\end{array}$} & \multirow[t]{2}{*}{ Tota } \\
\hline & & & $(\%)$ & $(\%)$ & & \\
\hline Tobacco products & 93 & 2 & 0 & 1 & 4 & 100 \\
\hline Alcohol & 81 & 12 & 2 & 4 & 1 & 100 \\
\hline Cannabis & 89 & 2 & 2 & 4 & 3 & 100 \\
\hline Sleeping pills & 93 & 4 & 1 & 1 & 1 & 100 \\
\hline Pain medications & 83 & 13 & 2 & 1 & 1 & 100 \\
\hline Average (\%) & 88 & 7 & 1 & 2 & 2 & 100 \\
\hline Average (F) & 277 & 21 & 4 & 7 & 6 & 315 \\
\hline
\end{tabular}

Study findings (Table 8) show that 13 percent of the respondents had in the past month failed to do what was normally expected of them due to the misuse of pain medications. Moreover, 12 percent who had used alcohol, 4 percent who had used sleeping pills, and 2 percent who had used tobacco products and cannabis had once or twice failed to do what was normally expected of them. Further on substance use, the study sought to establish whether the respondents had ever tried and failed to control, cut down, or stop using any of the substances listed.

Table 9 Ever Tried and Failed to Control, Cut Down or Stop Substance Use

\begin{tabular}{|l|c|c|c|}
\hline Substances & $\begin{array}{c}\text { No, Never } \\
(\boldsymbol{\%})\end{array}$ & Yes, in the past 6 months (\%) & $\begin{array}{c}\text { Yes, but not in the past 6 months } \\
(\%)\end{array}$ \\
\hline Tobacco products & 92 & 4 & 4 \\
\hline Alcohol & 78 & 11 & 5 \\
\hline Cannabis & 89 & 6 & 2 \\
\hline Sleeping pills & 92 & 6 & 2 \\
\hline Pain medication & 84 & 14 & 11 \\
\hline
\end{tabular}

Findings presented in Table 9 demonstrate that of those who had engaged in substance use, 92 percent used tobacco products and a similar percentage used sleeping pills, 89 percent who had used cannabis, 84 percent who had used pain medication, and 78 percent who had used alcohol had never tried and failed to control, cut down or stop using those substances. This shows that there were low levels of dependence on these substances.

The study used the resultant substance involvement scores to classify the risk level of the female students. Determination of the risk level was done based on the following classifications $(0-3=$ Lower Risk, $4-26=$ Moderate Risk and 27 and above $=$ High Risk). The study results are presented in Table 10.

Table 10 Levels of Risk for Harmful Use of Substances

\begin{tabular}{|l|c|c|}
\hline Level & Frequency & Percent \\
\hline Low & 188 & 39.7 \\
\hline Moderate & 105 & 33.3 \\
\hline High & 22 & 7.0 \\
\hline Total & $\mathbf{3 1 5}$ & $\mathbf{1 0 0 . 0}$ \\
\hline
\end{tabular}


Study findings (Table 10) reveal that 59.7 percent of the participants were classified as low risk, 33.3 percent as moderate risk while 7 percent were classified as high risk. These findings imply that though most of the respondents faced moderate to low risk, there was a significant population of female students that had a high risk of substance use.

Non-medical use was measured by whether participants had ever used any substance by injection for non-medical use within and without three months preceding the survey. The study sought to establish whether the participating female students had ever used any substance by injection.

Table 11 Have you used any drugs by injection?

\begin{tabular}{|c|c|c|}
\hline Response & Frequency & Percent \\
\hline No, never & 259 & 82 \\
\hline Yes, in the past 3 months & 9 & 3 \\
\hline Yes, but not in the past 3 months & 14 & 4 \\
\hline Non-response & 33 & 11 \\
\hline Total & $\mathbf{3 1 5}$ & $\mathbf{1 0 0}$ \\
\hline
\end{tabular}

Findings presented in Table 11 indicate that 82 percent of the participants had not engaged in any substance use through injection while 3 percent had engaged in substance use through injection in the three months before the study. Ten student leaders were interviewed. In this light, they were presented with various questions on substance use. The first question posed to them was, "what is the level of substance use among female students at KMTC?" Numerous responses were obtained. It was made manifest that there were high levels of use of various substances of choice among female students. These included sleeping pills and various forms of prescription medication. There were also some groups of female students who were involved in alcohol use in "girls clubs." These were groups of female students who exhibited high levels of "sisterhood," and had some form of consensus on behavioural choices including substance use and other risk-taking behaviours. Cigarette use was also common though among fewer female students. An example of the words of one of the students who said:

"Some girls hang up together and abuse alcohol and other substances together. They also pool resources together to enable them to afford the substances."

The student leaders were also presented with the question, "are there differences in substance use among female students of different age groups?" The findings showed that younger students tend to have higher tendencies to use substances of choice. In this regard, those in the first and second years of study (ages 18 to 21) had higher substance use behaviours.

Although some older students still used substances, a larger proportion seemed to have moved on from substances with the vast majority concentrating on their career choices. This was evidence in the words of one of the students who said:

"The younger students (freshers) have a lot of time and want to explore "life." Some have never had enough time to experiment with various substances. As a result, they are likely to try emerging substances. Others are not still focused on their studies and are at crossroads between being teenagers and adults. They are thus more likely to use drugs."

The students were asked if "there were differences in substance use among female students from different religions (i.e. Christianity, Islam, Hindu, etc.)?" The findings show that there were higher numbers of substance use among female students from Christian backgrounds compared to those from other faiths such as Islam and Hindu. However, this could be attributed to the fact that there were fewer students from the latter faiths. In addition, students from Muslim faiths were more conservative than those from the other faiths. However, some female students from some Christian sects such as Pentecostals and Evangelicals were also equally conservative and did not use substances compared to those from other Christian groups.

Moreover, students were presented with the question, "are there differences in substance use among female students based on the high school they attended (i.e. boarding, mixed day, national, county, sub-county, etc.)?” The findings show that students from mixed days tended to be more resilient to substance use than those from boarding schools. Students from boarding schools tended to use narcotic substances more than those from day schools. This could be attributable to influences in boarding schools by students from various backgrounds.

Lastly, most beginners in substance use came from boarding schools compared to those from mixed-day schools. When asked for an explanation of this trend, the interviewees said that confined and strict boarding schools protected some of the girls from learning about the consequences of substance use early in life. When they joined KMTC, they had all the freedom, independence and time to start exploring and experimenting. 
International Journal of Advances in Scientific Research and Engineering (ijasre), Vol 7 (9), September -2021

\subsection{Peer Domain Factors and Substance Use}

The study sought to determine the influence of peer domain factors on substance use among KMTC female students. To assess the peer domain factors, several factors were listed and the study participants were asked to indicate the extent to which the statements applied to them.

Table 12 Peer Domain Factors and Substance Use

\begin{tabular}{|l|c|c|c|c|c|}
\hline Statement & Not at all (\%) & $\begin{array}{c}\text { Small extent } \\
(\%)\end{array}$ & $\begin{array}{c}\text { Moderate } \\
\text { extent }(\%)\end{array}$ & $\begin{array}{c}\text { High } \\
\text { extent }(\%)\end{array}$ & $\begin{array}{c}\text { Very high } \\
\text { extent }(\%)\end{array}$ \\
\hline I want to be like my peers & 70 & 12 & 9 & 4 & 5 \\
\hline My friends use substances & 43 & 23 & 14 & 10 & 10 \\
\hline $\begin{array}{l}\text { My friends disapprove } \\
\text { substance use }\end{array}$ & 24 & 14 & 20 & 17 & 25 \\
\hline $\begin{array}{l}\text { I encounter peer influence to } \\
\text { use substances }\end{array}$ & 51 & 13 & 18 & 11 & 7 \\
\hline Average (\%) & 46 & 16 & 14 & 11 & 13 \\
\hline Average (F) & 145 & 50 & 44 & 35 & 41 \\
\hline
\end{tabular}

Study findings in Table 12 demonstrate that 70 percent of the respondents did not copy their peers at all, 43 percent had friends who did not use substances at all, 25 percent had friends who disapprove of substance use to a very high extent and 51 percent did not encounter peer influence to use substances at all. The interviewees were asked, "Are there differences in substance use among female students based on the friends they keep (peers)?" Most non-substance using students were initiated into the use of substances at KMTC.

Moreover, mobility to narcotics often depends on the kind of friends that one keeps. This is explained by the fact that access to substances is dependent on the availability of friends. Conversely, some friends discouraged peers from using substances. In this regard, having friends with conservative religious views militated against substance use among some female students. In this regard, one student leader said:

"There are instances in which students had conservative religious roommates in their hostels that discouraged them from using substances. This reduced the level of use of these substances."

It was thus made manifest that peers could either augment the substance use behaviours of female students and vice versa.

\subsection{Correlation Analysis for Peer Domain Factors and Substance Use}

The findings obtained show that there was a positive and significant relationship between substance use and peer domain factors (My siblings have a high influence on me, $r=0.547, \mathrm{p}<0.05$; I want to be like my peers, $r=0.340, \mathrm{p}<0.05$; My friends use substances, $r=0.500, p<0.05$; My friends disapprove substance use, $r=0.545, p<0.05$; I encounter peer influence to use substances, $\mathrm{r}=0.505, \mathrm{p}<0.05)$. Each of the various peer domain factors had positive and significant influences on substance use. 
International Journal of Advances in Scientific Research and Engineering (ijasre), Vol 7 (9), September -2021

Table 13 Correlation Analysis for Peer Domain Factors

\begin{tabular}{|c|c|c|c|c|c|c|c|}
\hline \multicolumn{8}{|c|}{ Correlations } \\
\hline & & $\begin{array}{c}\text { Substance } \\
\text { Use }\end{array}$ & $\begin{array}{l}\text { My siblings } \\
\text { have a high } \\
\text { influence on } \\
\text { me }\end{array}$ & $\begin{array}{c}\text { I want to be } \\
\text { like my } \\
\text { peers }\end{array}$ & $\begin{array}{c}\text { My friends } \\
\text { use } \\
\text { substances }\end{array}$ & $\begin{array}{l}\text { My friends } \\
\text { disapprove } \\
\text { of substance } \\
\text { use }\end{array}$ & $\begin{array}{l}\text { I encounter peer } \\
\text { influence to use } \\
\text { substances }\end{array}$ \\
\hline \multirow[t]{3}{*}{ Substance Use } & $\begin{array}{l}\text { Pearson } \\
\text { Correlation }\end{array}$ & 1 & $.547^{* *}$ & $.340^{* *}$ & $.500^{* * *}$ & $.545^{* * *}$ & $.505^{* *}$ \\
\hline & Sig. (2-tailed) & & .000 & .000 & .000 & .000 & .000 \\
\hline & $\mathrm{N}$ & 315 & 315 & 315 & 315 & 315 & 315 \\
\hline
\end{tabular}

\section{Source: Field data 2018}

\subsection{Regression Analysis}

Regression analysis was also utilised to test the study level to which the independent study variable affected the dependent variable. In this regard, the dependent variable, substance use was tested against peer factors, the independent variable.

\subsubsection{Model Summary for Peer Domain Factors}

The findings showed that the peer domains explained 30.4 percent of change in substance use among the female KMTC students (r squared $=0.304)$.

Table 14 Model Summary for Peer Domain Factors

\begin{tabular}{|l|r|r|r|r|}
\hline \multicolumn{7}{|c|}{ Model Summary } \\
\hline Model & \multicolumn{1}{|c|}{$\mathrm{R}$} & R Square & Adjusted R Square & Std. Error of the Estimate \\
\hline 1 & $.551^{\mathrm{a}}$ & .304 & .68737 \\
\hline \\
$\begin{array}{l}\text { a. Predictors: (Constant), I encounter peer influence to use substances, I want to be like my peers, My friends disapprove substance } \\
\text { use, My friends use substances }\end{array}$ \\
\hline
\end{tabular}

\subsubsection{Analysis of Variance for Peer Domain Factors}

As shown in Table 15, the peer domain factors statistically significantly predict substance use as shown by a significant $\mathrm{F}$ test $(\mathrm{F}=33.862, \mathrm{p}<0.05)$.

Table 15 Analysis of Variance for Peer Domain Factors

\begin{tabular}{|c|c|c|c|c|c|c|}
\hline \multicolumn{7}{|c|}{ ANOVA $^{b}$} \\
\hline \multicolumn{2}{|c|}{ Model } & Sum of Squares & $\mathrm{df}$ & Mean Square & $\mathrm{F}$ & Sig. \\
\hline \multirow[t]{3}{*}{1} & Regression & 63.996 & 4 & 15.999 & 33.862 & $.000^{\mathrm{a}}$ \\
\hline & Residual & 146.468 & 310 & .472 & & \\
\hline & Total & 210.463 & 314 & & & \\
\hline \multicolumn{7}{|c|}{$\begin{array}{l}\text { a. Predictors: (Constant), I encounter peer influence to use substances, I want to be like my peers, My friends disapprove } \\
\text { substance use, My friends use substances }\end{array}$} \\
\hline \multicolumn{7}{|c|}{ b. Dependent Variable: Substance Use } \\
\hline
\end{tabular}




\subsubsection{Regression Coefficients for Peer Domain Factors}

The findings also indicated that substance use had a statistically significant relationship with only one of the peer domain factors (My friends disapprove of substance use, $\mathrm{B}=0.379, \mathrm{t}=2.969, \mathrm{P}<0.05$ ). As such, it can be deduced that having friends who disapprove of substance use was the most important determinant of substance use among female students.

Table 16 Regression Coefficients for Peer Domain Factors

\begin{tabular}{|c|c|c|c|c|c|c|}
\hline \multicolumn{7}{|c|}{ Coefficients $^{a}$} \\
\hline \multirow{2}{*}{\multicolumn{2}{|c|}{ Model }} & \multicolumn{2}{|c|}{ Unstandardized Coefficients } & \multirow{2}{*}{$\begin{array}{c}\text { Standardized } \\
\text { Coefficients }\end{array}$} & \multirow[b]{2}{*}{$\mathrm{t}$} & \multirow[b]{2}{*}{ Sig. } \\
\hline & & $\mathrm{B}$ & Std. Error & & & \\
\hline \multirow[t]{5}{*}{1} & (Constant) & 2.066 & .095 & & 21.669 & .000 \\
\hline & I want to be like my peers & -.081 & .072 & -.121 & -1.125 & .261 \\
\hline & My friends use substances & -.011 & .124 & -.019 & -.089 & .929 \\
\hline & My friends disapprove substance use & .203 & .068 & .379 & 2.969 & .003 \\
\hline & $\begin{array}{l}\text { I encounter peer influence to use } \\
\text { substances }\end{array}$ & .173 & .113 & .295 & 1.529 & .127 \\
\hline
\end{tabular}

Source: Field data 2018

\section{CONCLUSIONS AND RECOMMENDATIONS}

\subsection{Conclusions}

Peer domain factors also had a significant influence on substance use among female students at KMTC. In this regard, the similarity between peers is critical in influencing behaviour. Therefore, having peers who do not use substances and having peers who disapprove of substance use is expected to lead in preventing female students from engaging in substance use. Conversely, having friends who use substances could lead to the use of the substances of choice among female students.

\subsection{Recommendations}

Based on the findings of the study, the following recommendations were made.

Prevention programs targeting female students to reduce risk factors associated with substance use are recommended. KMTC need to implement peer-led substance awareness campaigns that integrate life skills to enable students to resist substance use. KMTC need to engage the students in having peer support groups that create awareness and discourage substance use.

Access to help services was also recognised as key in protecting against substance use. The study recommends to the government and its agencies such as NACADA to step up their efforts in creating awareness on available support services for students engaging in substance use so that female students who engage in substance use can get help.

\section{REFERENCES}

[1]. WHO. (2016). The health and social effects of nonmedical cannabis use. Geneva: World Health Organization.

[2]. American Psychiatric Association. (2013). Diagnostic and statistical manual of mental disorder (5th Ed.). Washington: American Psychiatric Association.

[3]. Davis, S., \& Spillman, S. (2011). Reasons for Drug Abstention: A Study of Drug Use and Resilience. Journal of psychoactive drugs, 43(1), 14-19.

[4]. UNODC. (2017). World Drug Report 2017. Vienna: UNODC.

[5]. Blume, S. (2012). Understanding addiction disorders in women. In A. Graham, T. Schultz, \& V. Wilford (Eds.), Principles of Addiction Medicine (Vol. 2, pp. 1173- 1190). American Society of Addiction Medicine: Chevy Chase, MD.

[6]. Hodder, R. K., Freund, M., Bowman, J., Wolfenden, L., Gillham, K., Dray, J., \& Wiggers, J. (2016). Association between adolescent tobacco, alcohol and illicit drug use and individual and environmental resilience protective factors. Disease in Childhood, 6(11), 54-67.

[7]. NACADA. (2012). Rapid situation assessment of the status of drug and substance abuse in Kenya. Nairobi: NACADA.

[8]. Muriungi, S. K., Ndetei, D. M., Karanja, J., \& Matheka, C. W. (2013). Alcohol and substance abuse risk among students at the Kenya 
Medical Training College. Mental Health and Substance Use, 7(2), 125-133.

[9]. Kabiru, C. W., Beguy, D., Ndugwa, R. P., Zulu, F. M., \& Jessor, R. (2012). Making it”: Understanding adolescent resilience in two informal settlements (slums) in Nairobi, Kenya. Child and Youth Services, 33(1), 12-32.

[10]. Gathumbi, D. (2013). Prevalence of substance use among students in a Kenyan University: a preliminary report. East African Medical Journal, 76(1), 301-306.

[11]. Catalano, M., Miller, V., \& Hawkins, D. (2012). Ambiguity in black drinking norms: An ethnohistorical interpretation. In a. A. In Bennett L. (Ed.). New York: Plenum Press.

[12]. Brown, G., Johnston, L., Patrick, M., O'Malley, \& Jerald, G. (2010). Monitoring the Future National Results on Adolescent Drug Use: Overview of Key Findings. Available from http://www.monitoringthefuture.org; online

[13]. Bronfenbrenner, U. (1977). Toward an experimental ecology of human development. American Psychologist, 32(1), 513-531.

[14]. Bronfenbrenner, U. (1979). The ecology of human development: Experiments by nature and design. Cambridge: Harvard University Press.

[15]. Bronfenbrenner, U. (1986). Recent advances in research on the ecology of human development. In R. Silbereisen, K. Eyferth, \& G. Rudinger (Eds.), Development as action in context: Problem behaviour and normal youth development (p. 1). New York: Springer.

[16]. Paquette, D., \& Ryan, J. (2011). Bronfenbrenner's Ecological Systems Theory. Human Ecology, 39(2), 16-20.

[17]. Pandian, R. D., \& Lakshmana, G. (2017). Risk and resilience factors for substance use among street adolescents: Assessment and development of an integrative model. Asian Social Work and Policy Review, 11(3), 216-233.

[18]. VicHealth. (2015). Current theories relating to resilience and young people: a literature review. Melbourne: Victorian Health Promotion Foundation.

[19]. Parry, S. (2014). Drug use prevention among young people: A review of reviews. London: National Institute for Health and Clinical Excellence.

[20]. Collings, P., \& Magojo, S. (2015). Risk and resilience factors for substance use among street adolescents: Assessment and development of an integrative model. Asian Social Work and Policy Review, 11(3), 216-233.

[21]. Jason, T. (2011). Adolescent Drug Abuse in Kenya: Impact on Reproductive Health. Nairobi: New World Printers.

[22]. Kobasa, P. (2013). Cannabis use before age 15 and subsequent executive functioning. British Journal of Psychiatry, $198(6), 442-447$.

[23]. Eggun, H., \& Vaughan, L. (2014). What predicts psychological resilience after disaster? The role of demographics, resources, and life stress. Journal of Consulting and Clinical Psychology, 75(5), 671-682.

[24]. Bernard, A. (2014). Personal characteristics and resilience and its consequences: conceptual issues and empirical illustrations. Journal of Personality, 77(6), 1645-1676.

[25]. Search Institute. (2011). The prevention of substance use, risk and harm in Australia: A review of the evidence. Perth: Search Institute.

[26]. Henderson, S. (2013). A review of 25 long-term adolescent tobacco and other drug use prevention program evaluations. Preventive Medicine, 37(1), 451-474.

[27]. Good, P., \& McKay, B. (2012). Interventions to reduce the harm associated with adolescent substance use. An international review. Lancet, 369(1), 1391-1401.

[28]. Bot, A. (2015). A feminist approach to substance abuse treatment and service delivery. Social Work in Health Care, 19(3-4), 67-83.

[29]. Nicolas, J. (2011). Research Design: Qualitative, Quantitative and Mixed Approaches (2nd Ed.). Thousand Oaks: Sage.

[30]. Yamane, T. (1967). Statistics: An Introductory Analysis (2nd Ed.). New York: Harper and Row.

[31]. Cooper, D., \& Schindler, P. (2011). Business Research Methods (11th Ed.). New York: McGraw-Hill Education.

[32]. WHO. (2010). WHO-ASSIST V3.0. Geneva: WHO.

[33]. Mugenda, A. G., \& Mugenda, O. M. (2012). Research methods: Qualitative and qualitative approaches. Nairobi: ACTS Press. 